06

\title{
Нанокомпозитные полимерные структуры для оптических сенсоров сероводорода
}

\author{
(C) А.А. Сергеев, ${ }^{1,2}$ A.Ю. Мироненко, ${ }^{3}$ А.Е. Назиров, ${ }^{2,3}$ А.А. Леонов, ${ }^{1,2}$ С.С. Вознесенский ${ }^{1,2}$ \\ ${ }^{1}$ Институт автоматики и процессов управления ДВО РАН, \\ 690041 Владивосток, Россия \\ ${ }^{2}$ Дальневосточный федеральный университет, \\ 690000 Владивосток, Россия \\ ${ }^{3}$ Институт химии ДВО РАН, \\ 690022 Владивосток, Россия \\ e-mail: Sergeev@iacp.dvo.ru
}

(Поступило в Редакцию 27 декабря 2016 г.)

\begin{abstract}
Представлены результаты исследований нанокомпозитных покрытий на основе наночастиц золота и серебра, in situ восстановленных в пленке полисахарида хитозана. Установлено, что в присутствии молекул сероводорода происходит уменьшение энергии максимума плазмонного резонанса наночастиц, величина которого пропорциональна концентрации аналита. Предел обнаружения сероводорода составил 0.1 ppm для нанокомпозита хитозан/серебро и 5 ррт для нанокомпозита хитозан/золото.
\end{abstract}

DOI: 10.21883/JTF.2017.08.44739.2153

Каталитическая активность наночастиц благородных металлов обеспечила их широкое применение в качестве чувствительных элементов электрохимических сенсоров. В области оптики и нанофотоники металлические наночастицы могут использоваться в качестве передатчика энергии, например, при реализации FRETметода [1] или для локализации оптического поля на наноразмерных масштабах [2]. Так, наночастицы серебpa, нанесенные на поверхность углеродной нанотрубки, используются для электрохимического определения газообразного сероводорода [3] или диоксида азота [4] в случае нанесения на пленку диоксида титана. Суспензии серебряных наночастиц также используются для определения концентрации пероксида водорода и глюкозы $[5,6]$.

Одним из перспективных направлений в сенсорике является использование эффекта плазмонного резонанса металлических наночастиц, характеристики которого могут изменяться в присутствии молекул определяемого вещества (аналита). Реализуются различные методы фиксации наночастиц [7], среди которых простотой выделяется метод in situ восстановления в диэлектрической матрице [8].

Сероводород - это токсичный газ, являющийся побочным продуктом деятельности промышленных предприятий, связанных с нефтяной переработкой, очисткой сточных вод и текстильной промышленностью [9]. Поскольку сероводород так же является продуктом жизнедеятельности живых организмов, высокоточное определение его концентрации требуется при решении задач, связанных с контролем качества пищевых продуктов и проведения биомедицинских исследований [10-14].

В настоящей работе представлены результаты исследований нанокомпозитных полимерных структур для оптических сенсоров сероводорода на основе наночастиц золота и серебра.
Для получения нанокомпозитных структур использовался $1.5 \%$ среднемолекулярный хитозан с молекулярной массой 400-600 kDa и степенью деацитилирования 75-85\% (ОАО Биопрогресс, Россия). В качестве растворителя использовалась ледяная уксусная кислота с отношением НАс:хитозан, равным 1:1 по массе. Раствор выдерживался в течение $2 \mathrm{~h}$ при температуре $50^{\circ} \mathrm{C}$ и постоянном перемешивании. Для удаления нерастворимых частиц и дегазирования полученных растворов проводилось последовательное центрифугирование в течение $1 \mathrm{~h}$ при $4000 \mathrm{rpm}$, после чего растворы фильтровались через целлюлозные фильтры с диаметром пор $1.2 \mu \mathrm{m}$. В качестве подложек для нанесения покрытий использовались стеклянные эффузионные волноводы (толщина волноводного слоя $t=3 \mu \mathrm{m}$, количество поддерживаемых мод $\left.-2\left(n_{\mathrm{eff}}(\mathrm{TE} 0)=1.522592 ; n_{\mathrm{eff}}(\mathrm{TE} 1)=1.516096\right)\right)$. Перед нанесением покрытий подложки обрабатывались смесью $\mathrm{H}_{2} \mathrm{O}_{2} / \mathrm{NH}_{3} / \mathrm{H}_{2} \mathrm{O}(1: 1: 1)$ при $80^{\circ} \mathrm{C}$ на ультразвуковой бане в течении $30 \mathrm{~min}$, после чего тщательно промывались и высушивались при $120^{\circ} \mathrm{C}$. Нанесение однородных пленок хитозана осуществлялось методом центрифугирования из водных растворов полимера на установке Laurell WS-400B-6NPP-LITE (CШA). Pacтвор хитозана равномерно распределялся по поверхности подложки, которая затем вращалась в течение $2 \mathrm{~min}$ со скоростью $3500 \mathrm{rpm}$.

Для перевода пленок ацетата хитозана в нейтральную форму полученные покрытия выдерживались в 5\% растворе аммиака в течение $10 \mathrm{~s}$ и промывались под проточной дистиллированной водой, после чего сушились при $80^{\circ} \mathrm{C}$. Для внедрения наночастиц золота и серебра подложки с покрытием хитозана в нейтральной форме толщиной $150 \mathrm{~nm}$ погружались в растворы $\mathrm{H}\left[\mathrm{AuCl}_{4}\right]$ или $\mathrm{AgNO}_{3}$ концентрацией 0.0001 и $0.1 \mathrm{M}$ соответственно на $20 \mathrm{~min}$. После внедрения в покрытия 

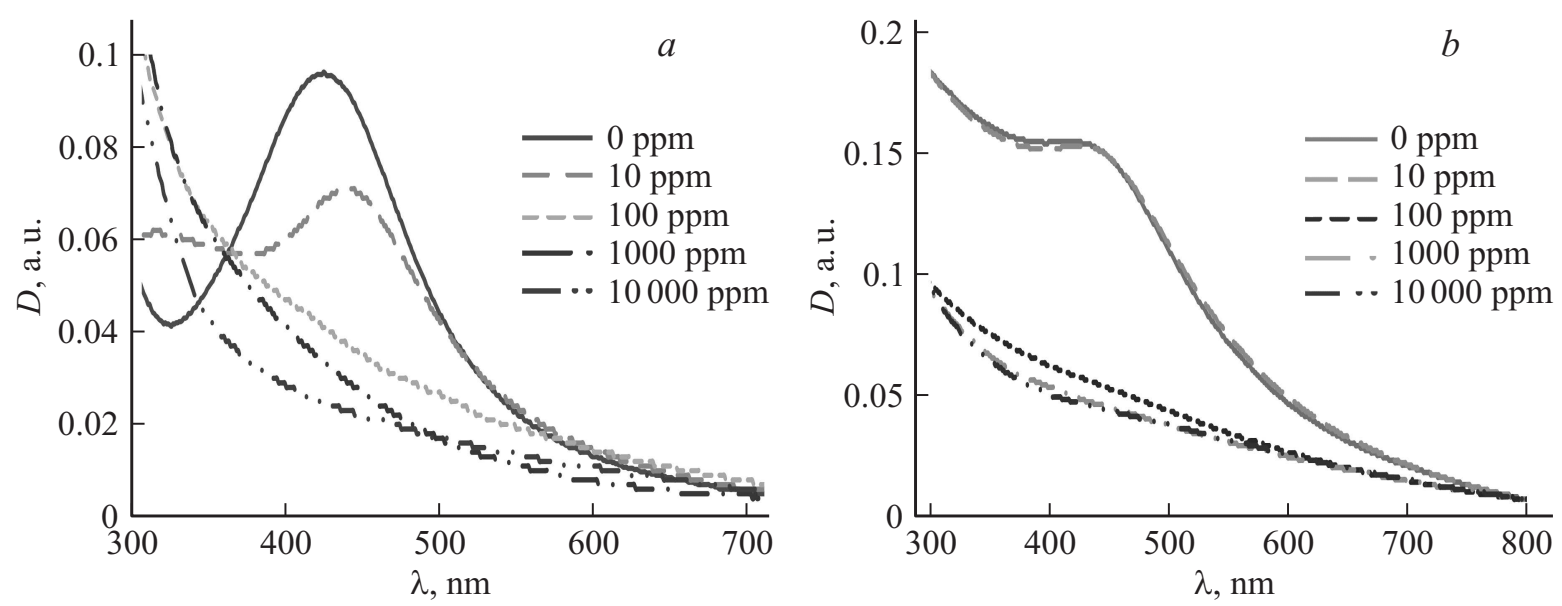

Рис. 1. Спектральные характеристики нанокомпозитных покрытий в атмосфере сероводорода: $a-$ покрытие хитозан/серебро, $b$ - покрытие хитозан/золото.
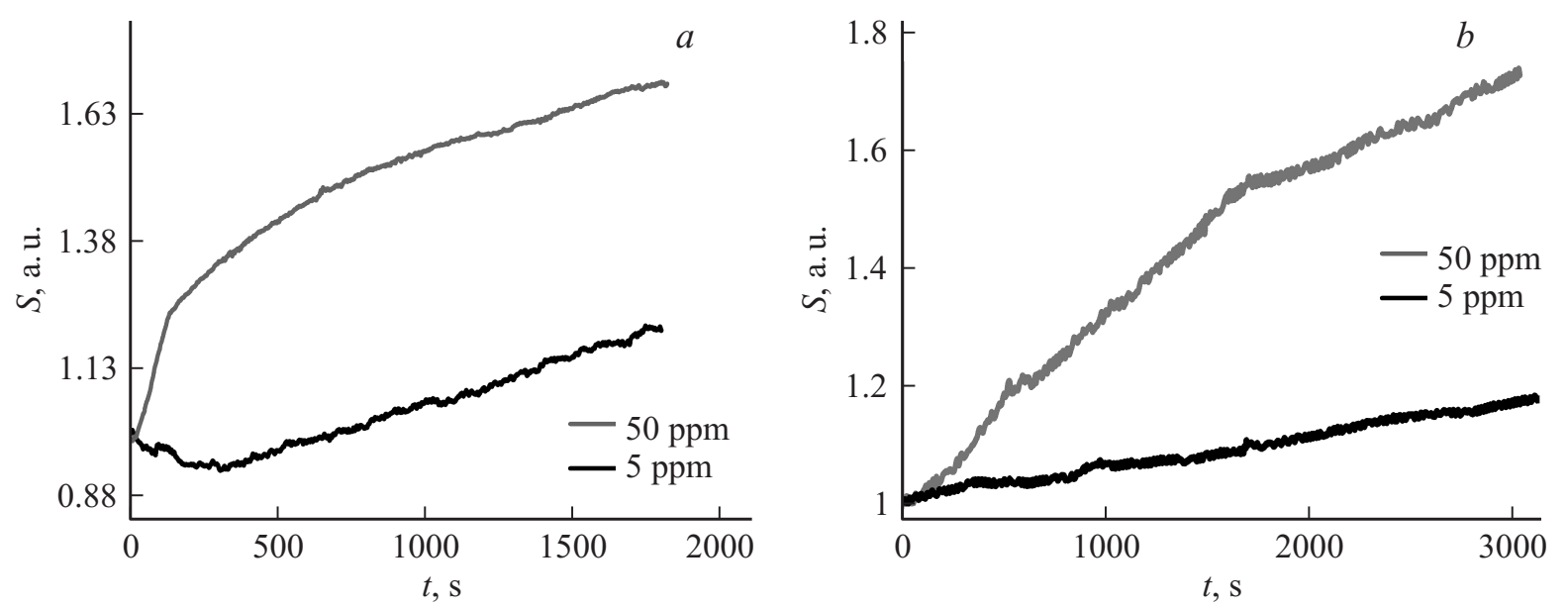

Рис. 2. Динамика сенсорного отклика нанокомпозитных покрытий на присутствие сероводорода различных концентраций: $a-$ хитозан/серебро, $b-$ хитозан/золото.

ионов металлов-прекурсоров подложки тщательно промывались проточной дистиллированной водой и погружались в $0.01 \%$ раствор $\mathrm{NaBH}_{4}$ на $10 \mathrm{~min}$, после чего вновь промывались дистиллированной проточной водой в течение $1 \mathrm{~min}$. Мониторинг процесса формирования наночастиц металлов и кинетика окисления металлов в атмосфере сероводорода осуществлялись методом УФвидимой спектроскопии на спектрофотометре Varian Cary 5000i.

Требуемая концентрация сероводорода создавалась путем растворения сульфида натрия в дистиллированной воде при соотношении $0.1,0.01,0.001$ и 0.0001 М. Полученная концентрация сероводорода определялась газоанализатором „Коллион 1B“, с пределом обнаружения $0.07 \mathrm{ppm}$ (0.01 MAC maximum allowable concentration). Измерения проводились при $21^{\circ} \mathrm{C}$ и уровне относительной влажности $30 \%$.

Сенсорные характеристики в волноводном режиме исследовались на экспериментальной установке, опи- санной в [15]. В качестве источников излучения использовались твердотельные лазерные источники с максимумом излучения на $\lambda=442$ и $532 \mathrm{~nm}$ для исследования нанокомпозитов хитозан/наночастицы серебра и хитозан/наночастицы золота соответственно. Выбор указанных лазерных источников был обусловлен наибольшим соответствием длины волны эмиссии к положению максимума плазмонного резонанса исследуемых наночастиц.

Хитозан является природным биосовместимым, биоразлагаемым и нетоксичным полимером, хорошие пленкообразующие свойства которого делают его перспективным кандидатом для создания нанокомпозитных покрытий. Благодаря присутствию аминогрупп пленки хитозана обладают способностью сорбировать катионные и анионные формы благородных металлов [16], а растворы полисахарида успешно используются для стабилизации металлических наночастиц в растворах [17]. Комбинация указанных свойств обусловила использование хитозана 
как матрицы для синтеза металл-полимерных композитов методом in situ восстановления ионов металловпрекурсоров в полимерной ионно-обменной матрице.

Спектроскопия волноводных мод [8], в свою очередь, является хорошо изученным инструментом для исследования сенсорных характеристик тонких пленок. Взаимодействие поля распространяющейся волноводной моды с покрытием, сформированным на поверхности волновода, обеспечивает высокоточную регистрацию степени изменения оптических характеристик покрытия. При этом диссипация энергии на плазмонный резонанс наночастиц накладывает некоторые ограничения на толщину покрытия. Экспериментально нами было установлено, что покрытие толщиной $150 \mathrm{~nm}$ обеспечивает наилучшее соотношение сигнал/шум и является оптимальным для проведения исследований.

Были получены оптически прозрачные покрытия, максимум плазмонного резонанса которых находится в районе $410 \mathrm{~nm}$ для наночастиц серебра и $530 \mathrm{~nm}$ для наночастиц золота (рис. 1). Основное преимущество предложенного нами метода формирования нанокомпозитных покрытий путем восстановления наночастиц непосредственно в пленке полимера заключается в наличии единственного пика плазмонного резонанса частиц. Данный факт свидетельствует о сферической форме и высокой гомогенности получаемых наночастиц [18]. Металлические наночастицы в полимерной матрице стабильны и сохраняют свои характеристики в течение длительного периода времени. Газопроницаемость хитозана обеспечивает химическое взаимодействие между частицами и сероводородом, что приводит к изменению оптических характеристик нанокомпозитного покрытия в присутствии молекул аналита. При этом в случае наночастиц серебра (рис. 1,a) низкие концентрации сероводорода приводят к сдвигу максимума плазмонного резонанса с последующим его исчезновением при повышении концентрации. В случае наночастиц золота (рис. $1, b$ ) сдвига максимума плазмонного резонанса при низких концентрациях сероводорода не было обнаружено, происходит только уменьшение его величины.

Результаты исследования спектральных характеристик дают только качественный характер оптического отклика покрытий на присутствие молекул сероводорода. Для количественной оценки сенсорного отклика и определения динамических характеристик покрытия использовался метод спектроскопии волноводных мод. На рис. 2 представлены зависимости мощности прошедшего через волновод излучения от длительности воздействия сероводорода с различной концентрацией.

Можно видеть, что до напуска аналита нанокомпозитное покрытие поглощает часть направляемого волноводом излучения и мощность прошедшего через волновод излучения минимальна. В присутствии молекул сероводорода покрытие начинает просветляться и мощность прошедшего излучения увеличивается. При этом на больших концентрациях сероводорода (порядка $50 \mathrm{ppm} \approx 7 \mathrm{MAC)}$ величина сенсорного отклика $S$,

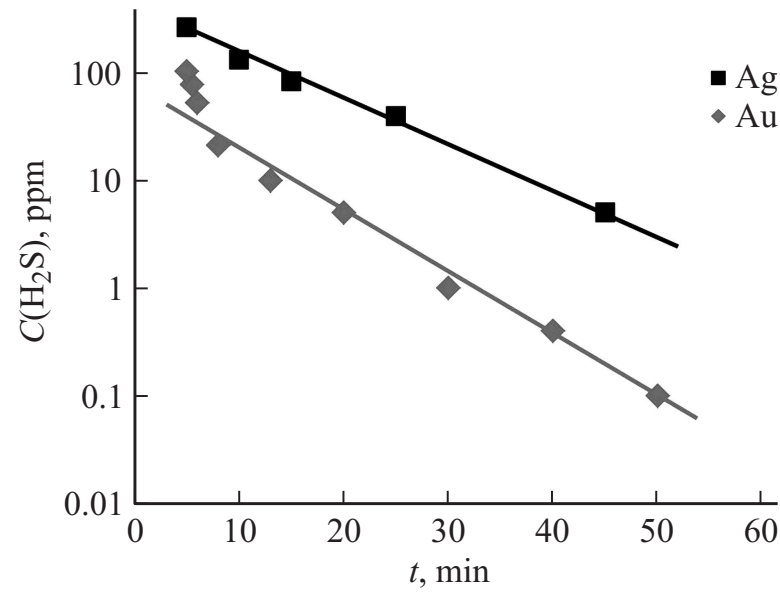

Рис. 3. Зависимость времени отклика нанокомпозитных покрытий от концентрации сероводорода: $a-$ хитозан/серебро, $b$ - хитозан/золото.

определяемая как отношение текущего значения выходной мощности к первоначальному, для покрытий хитозан/серебро и хитозан/золото имеет примерно одинаковое значение. В то же время при концентрациях ниже МАС нанокомпозитное покрытие хитозан/серебро имеет большую чувствительность, и при концентрациях аналита 5 ррm наблюдается первоначальное уменьшение величины выходной мощности (рис. 2,a), связанное со сдвигом максимума плазмонного резонанса (рис. 1, a).

При продолжительном воздействии сероводорода наступает режим насыщения, и выходная мощность перестает изменяться. Время, необходимое для достижения насыщения, определяет время отклика покрытия на присутствие аналита, а минимальная концентрация аналита, приводящая к изменению выходной мощности, определяет чувствительность покрытия. Поскольку серебряные наночастицы более активны по отношению к сероводороду, чем золотые, нанокомпозитные покрытия хитозан/серебро демонстрируют большую чувствительность. Для покрытий с наночастицами серебра характерен линейный характер зависимости времени отклика от логарифма концентрации аналита в диапазоне 0.1-20 ppm (0.06-15 МАС). В свою очередь, покрытия хитозан/золото имеют линейный отклик в диапазоне концентраций 5-300 ppm (рис. 3).

Результаты проведенных исследований демонстрируют принципиальную возможность использования нанокомпозитных покрытий на основе наночастиц благородных металлов in situ восстановленных в хитозановой матрице для задач оптической сенсорики сероводорода в широком диапазоне концентраций. Менее чувствительные, но имеющие больший рабочий диапазон, покрытия хитозан/золото могут быть использованы для контроля промышленных газовых сред. Покрытия хитозан/наночастицы серебра имеют большую чувствительность, и необратимый характер сенсорного отклика делает их перспективными для применения в качестве 
„счетчика молекул“ сероводорода в системах определения свежести продуктов.

Обработка спектральных характеристик наночастиц золота в атмосфере воздуха и сероводорода выполнена в рамках проекта Плана НИР № 0262-2014-0015; обработка спектральных характеристик наночастиц серебра в атмосфере воздуха и сероводорода выполнена в рамках гранта президента № МК-8089.2016.2; исследования динамики сенсорного отклика и определение зависимости времени отклика покрытий от концентрации сероводорода проводились при поддержке гранта Российского научного фонда (соглашение № 14-50-00034).

\section{Список литературы}

[1] Dulkeith E., Morteani A.C., Niedereichholz T., Klar T.A., Feldmann J., Levi S.A., van Veggel F.C.J.M., Reinhoudt D.N., Moller M., Gittins D.I. // Phys. Rev. Let. 2002. Vol. 89. N 20. P. 203002.

[2] Novotny L., Van Hulst N. //Nat. Photonics. 2011. Vol. 5. N 2. P. 83-90.

[3] Yang X., Li L., Yan F. // Sens. \& Act. B. Chem. 2010. Vol. 145. P. 495-500.

[4] Serra A., Re M., Palmisano M., Antisari M.V., Filippo E., Buccolieri A., Manno D. // Sens. \& Act. B. Chem. 2010. Vol. 145. P. 794-799.

[5] Filippo E., Serra A., Manno D. // Sens. \& Act. B. Chem. 2009. Vol. 138. P. 625-630.

[6] Serra A., Filippo E., Re M., Palmisano M., Vittori-Antisari M., Buccolieri A., Manno D. // Nanotechnology. 2009. Vol. 20, N 16. P. 165501.

[7] Kango S., Kalia S., Celli A., Njuguna J., Habibi Y., Kumar R. // Prog. Pol. Sci. 2013. Vol. 38. N 8. P. 1232-1261.

[8] Mironenko A., Modin E., Sergeev A., Voznesenskiy S., Bratskaya S. // Chem. Eng. J. 2014. Vol. 244. P. 457-463.

[9] Kim K.-H., Choi Y., Jeon E., Sunwoo Y. // Atmos. Environ. 2005. Vol. 39. P. 1103-1112.

[10] Dodge M.E., Lum L. // Annu. Rev. Pharmacol. Toxicol. 2011. Vol. 51. P. 289-310.

[11] Kameneva P.A., Imbs A.B., Orlova T.Yu. // Toxicon. 2015. Vol. 98. P. 1-3.

[12] Kulchin Yu.N., Mayor A.Yu., Proschenko D.Yu., Zhizhchenko A.Yu., Golik S.S., Babiy M.Yu., Mirochnik A.G. // Quant. Electron. 2015. Vol. 45. N 5. P. 477-481.

[13] Golik S.S., Ilyin A.A., Babiy M.Yu., Biryukova Yu.S., Lisitsa V.V., Bukin O.A. // Plasma Sci. Tech. 2015. Vol. 17. N 11. P. 975-978.

[14] Ilyin A.A., Golik S.S., Shmirko K.A. // Spectrochim. Acta Part B. 2015. Vol. 112. P. 16-22.

[15] Voznesenskiy S.S., Sergeev A.A., Mironenko A.Y., Bratskaya S.Y., Kulchin Y.N. // Sensors and Actuators B: Chemical. 2013. Vol. 188. P. 482-487.

[16] Bratskaya S.Y., Azarova Y.A., Matochkina E.G., Kodess M.I., Yatluk Y.G., Pestov A.V. // Carbohydrate Pol. 2012. Vol. 87. N 1. P. 869-875.

[17] Tiwari A.D., Mishra A.K., Mishra S.B., Arotiba O.A., Mamba B.B. // Int. J. Biol. Macromol. 2011. Vol. 48. N 4. P. 682-687.

[18] Spano F., Massaro A., Cingolani R., Athanassiou A. // Microelectronic Engineering. 2011. V. 88. N 8. P. 2763-2766. 